\title{
Scalable manufacturing processes for solid lipid nanoparticles
}

Giulia Anderluzzi ${ }^{1}$, Gustavo Lou ${ }^{1}$, Yang Su² and Yvonne Perrie ${ }^{1^{*}}$

${ }^{1}$ Strathclyde Institute of Pharmacy and Biomedical Sciences, University of Strathclyde, Glasgow G4 ORE

${ }^{2}$ Microfluidics International Corporation, Westwood, Massachusetts, 022090, USA

*Corresponding author

\section{Abstract}

Solid lipid nanoparticles offer a range of advantages as delivery systems, but they are limited by effective manufacturing processes. Within this study we outline a high-throughput and scalable manufacturing process for solid lipid nanoparticles. The solid lipid nanoparticles were formulated from a combination of Tristearin and 1,2-Distearoyl-phosphatidylethanolamine-methyl-polyethyleneglycol conjugate-2000 and manufactured using the M-110P Microfluidizer ${ }^{\circledR}$ processor (Microfluidics Inc, Westwood, Massachusetts, US). The manufacturing process was optimized in terms of the number of process cycles (1 to 5$)$ and of process pressure change $(20,000$, 25,000 and 30,000 psi). The solid lipid nanoparticles were purified using tangential flow filtration, and they were characterized in terms of their size, PDI, Z-potential and protein loading. At-line particle size monitoring was also incorporated within the process train. Our results demonstrate that solid lipid nanoparticles can be effectively manufactured using this process at pressures of 20,000 psi with as little as 2 process passes, with purification and removal of non-entrapped protein achieved after 12 diafiltration cycles. Furthermore, the size could be effectively monitored at-line to allow rapid process control monitoring or product validation. Using this method, protein loaded solid lipid nanoparticles containing a low (1\%) and high (16\%) Pegylation were manufactured, purified and monitored for particle size using an AT-line system demonstrating a scalable process for the manufacture of these nanoparticles.

Key Words: $\quad$ Solid lipid nanoparticles, Microfluidizer processor, High-throughput manufacturing, protein delivery

\section{GRAPHICAL ABSTRACT}

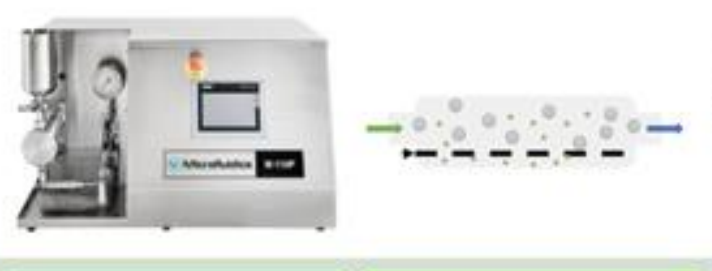

Manufacture

Purify

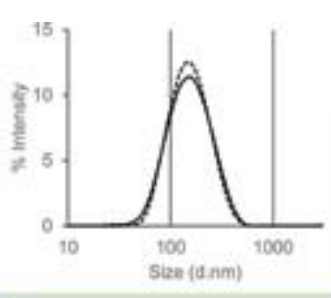

Monitor

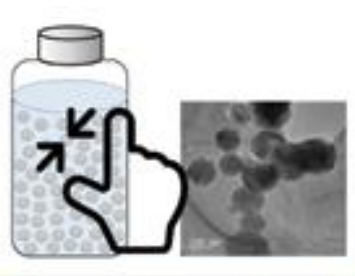

SLN product 


\section{Introduction}

In the development of nanomedicines, there is a wide range of delivery systems available including polymer based systems, protein based systems and lipid based systems. Within the lipid area, liposomes, emulsions and solid lipid nanoparticles can all be formulated to delivery drugs in a controlled and/or targeting mechanism, with each system offering advantages depending on the drug to be delivered, the rate of delivery, the route of administration and the target site. The use of solid lipids to develop solid lipid nanoparticles (SLNs) offers the potential for longer controlled release compared to emulsions and liposomes, because the drug mobility in these systems is reduced. Solid lipid nanoparticles consist of solid hydrophobic core with a monolayer coating of phospholipid. The solid core contains drug dissolved or dispersed in the solid high melting lipid matrix with the hydrophobic chains of phospholipids also embedded in this matrix ${ }^{(1)}$. Due to their lipidic nature, solid lipid nanoparticles are biocompatible and they can be manufactured without the use of organic solvents, which is also advantageous. ${ }^{(2)}$ However, solid lipid nanoparticles have limitations including lack of scale-up manufacturing processes and poor drug loading capacity. ${ }^{(3)}$

Currently, there are several formulations on the market based on lipids including a range of liposomal formulations (e.g. Doxil, Ambisome, Myocet) and lipid nanoemulsions such as Diazemuls, Diazepam-Lipuro and Etomidate-Lipuro ${ }^{(4)}$. The advantage of the both the liposomal systems and emulsions is the reduced drug side effects, e.g. off-target toxicity (e.g. Doxil) and pain of injection and inflammation at the injection site (e.g. diazepam). Although these systems have an excellent tolerability, the number of products on the market remains relatively low. This is based on manufacturing complexity and cost, in the case of liposomes, and with emulsions it is the physical instability which can be caused by the incorporated drug. In addition, the registered oils such as soybean oil, medium chain triglycerides and long chain triglycerides show an insufficient solubility for drugs of possible interest to be incorporated into emulsions ${ }^{(5)}$. In contrast, solid lipid nanoparticles can offer similar advantages to liposomes and emulsion based systems. However, currently there are no clinically approved solid lipid nanoparticle-based medical products.

In terms of their characteristics, generally, the solid lipid nanoparticle lipid matrix determines the pharmaceutical properties of the particles. Currently, stabilizers such as surfactants, co-surfactants and coating materials are widely employed in solid lipid nanoparticle formulations. Antioxidants, electrolytes, preservatives, viscosity enhancing agents, adhesives, absorption enhancers and other excipients can also be added to improve formulations attributes. For example, a combination of Tristearin and pegylated lipids can be used to formulate solid lipid nanoparticles; Tristearin or glyceryl tristearate is a triglyceride derived from three units of stearic acid, widely used in the pharmaceutical filed for its high biocompatibility and biodegradability and approved for oral or parental administration ${ }^{(6)}$. Poly (ethylene glycol)-distearoylphosphatidylethanolamine (PEG-DSPE) is a linear PEG phospholipid with saturated C18 stearoyl fatty acid ${ }^{(7)}$. Once incorporated in the particle, the PEG shell remains on the surface of the matrix and it can generate a hydrophilic coating which potentially reduces the in vivo clearance of carriers and their opsonisation by plasma proteins. The presence of PEG-DSPE could prolong the body circulation time of the carrier and release drugs at a sustained rate in an optimal range of drug concentrations.

Despite the advantages of solid lipid nanoparticles and the variety of formulations that can be explored, there remains a lack of cost-effective and scalable production methods and this has hampered the development of 
solid lipid nanoparticles. Current manufacturing and formulations approaches can be classified into three main groups - high energy approaches, low-energy approaches and methods employing organic solvents ${ }^{(8)}$ and a range of examples of formulations, their method of manufacture and their drug loading is outlined in Table 1 . This includes emulsification, extrusion/homogenisation, solvent evaporation methods and the adoption of supercritical fluids. Depending on the method of manufacture and the drug loaded, drug loading varies widely and production must be optimized for the given formulation. However, with many of these methods, dispersion quality is often compromised by the presence of micro particles.

To overcome these technical issues, we have investigated the application of high shear mixing as an innovative manufacture approach to produce protein (Ovalbumin; OVA) loaded solid lipid nanoparticles. One of the key features of high shear processing is the combination of high pressure delivery (which converts into kinetic energy) of the feed-stock into the interaction $Y$-shaped chamber ${ }^{(24-26)}$. The $Y$ shape of the chamber separates the stream in two micro-channels. The product stream collides upon itself, producing impaction and shear which reduces the particle size and polydispersity, and by controlling the process parameters (pressure and number of cycles) particle size can be controlled. ${ }^{(27-28)}$ An additional advantage of this system is the direct scalability of the process from bench to manufacture. Indeed, many papers reported the application of high shear processing for drug carriers manufacturing, especially emulsions, polymer particles, crystalloid solids and liposomes. ${ }^{(29-33)}$ For example, soy lecithin based liposomes were demonstrated to have a diameter below $50 \mathrm{~nm}$ and low polydispersity after the homogenization process. ${ }^{(34-35)}$ Furthermore, the Microfluidics M110P was used for particles size reduction of three different liposome formulations composed of 1) hydrogenated soy phosphatidylcholine, 1,2-dioleoyl-3-trimethylammonium-propane and cholesterol, 2) 1,2-dimyristoyl-snglycero-3-phosphocholine, 1,2-dimyristoyl-3-trimethylammonium-propane (DMTAP) and cholesterol, or 3) egg phosphatidylcholine, DMTAP and cholesterol. All three of these liposome formulations were shown to be monodisperse and highly stable, with diameter reduced to sub-micron sizes after 3 passages through the Microfluidizer. ${ }^{(36)}$ Similarly, this technology has been employed for silica nanoparticle manufacturing and for particles deagglomerating study, with encouraging results for both applications ${ }^{(37)}$. Given the positive results with other particulate systems, the aim of this work was to investigate and develop a scalable manufacturing process for solid lipid nanoparticles using the Microfluidizer technology.

\section{Materials and Methods}

\subsection{Materials}

Tristearin (Grade II-S, $\geq 90 \%$ ) and trifluoroacetic acid (TFA) were obtained from Sigma-Aldrich Company Itd, Poole, UK. 1,2-Distearoyl-phosphatidylethanolamine-methyl-polyethyleneglycol conjugate-2000 (DSPE-mPEG-2000) was obtained from Lipoid GmbH (Ludwigshafen Germany). Ethanol and methanol were obtained from Fisher 141 Scientific UK, Loughborough, UK. TRIS Ultra-Pure was obtained from ICN 142 Biomedicals, Inc., Aurora, Ohio. Phosphate-buffered saline (PBS) and Albumin from chicken egg (OVA), were obtained from Sigma-Aldrich Company Itd, Poole, UK. Sephadex G-75 size exclusion columns were obtained from GE Healthcare Life Science Little Chalfont-Buckinghamshire, UK.

\subsection{Preparation of solid lipid nanoparticles}

Solid lipid nanoparticles were prepared using the M-110P Microfluidizer ${ }^{\circledR}$ (Microfluidics Inc, Westwood, Massachusetts, US). mPEG-DSPE-2000 ( 1 or $16 \% \mathrm{w} / \mathrm{w}$ ) was dissolved in $10 \mathrm{mM}$ TRIS buffer at pH 7.4 and heated 
up at $75^{\circ} \mathrm{C}$. Tristearin $1.3 \mathrm{mg} / \mathrm{mL}$ was melted at $75^{\circ} \mathrm{C}$ and the liquid mass was emulsified with the aqueous phase under vigorous stirring. Buffer solution $\left(75^{\circ} \mathrm{C}\right.$ ) was added to the $\mathrm{O} / \mathrm{W}$ emulsion to a final volume of $75 \mathrm{~mL}$. The emulsion was loaded in the inlet reservoir of an M-110P Microfluidizer processor and the effect of the number of process cycles ( 1 to 5 ) and of process pressure change $(20,000,25,000$ and 30,000 psi) were investigated. The size, PDI and Z-potential were measured with Zetasizer Nano ZS and Zetasizer AT (Malvern Instruments Ltd).

OVA loaded Tristearin: mPEG-DSPE (5:1 w/w) solid lipid nanoparticles were similarly prepared: mPEG-DSPE-2000 $16 \% \mathrm{w} / \mathrm{w}$ was dissolved in $10 \mathrm{mM}$ TRIS buffer at $\mathrm{pH} 7.4$ and heated up at $75^{\circ} \mathrm{C}$. To formulate loaded particles, Ovalbumin (0.1, 0.5 and $1 \mathrm{mg} / \mathrm{mL}$; OVA) was added to the aqueous phase. Tristearin $1.3 \mathrm{mg} / \mathrm{mL}$ was melted at $75^{\circ} \mathrm{C}$ and the liquid mass was emulsified with the aqueous phase under vigorous stirring. Buffer solution $\left(75^{\circ} \mathrm{C}\right)$ was added to the $\mathrm{O} / \mathrm{W}$ emulsion to a final volume of $75 \mathrm{~mL}$. The emulsion was loaded in the inlet reservoir of an M-110P Microfluidizer processor to reduce particles size.

\subsection{Purification and concentration of solid lipid nanoparticles using Tangential Flow Filtration}

Tangential Flow Filtration (KR2i TFF System ${ }^{\circledR}$; column cut off $750 \mathrm{kD}$ ) as a means of purification and concentration of samples after microfluidizer homogenization. The concentration process after high-shear mixing was performed with a $75-\mathrm{ml}$ feed volume of solid lipid nanoparticles dispersion $(0.5 \mathrm{mg} / \mathrm{mL})$ and the TMP maintained at $10 \mathrm{psi}$. The retentate was circulated back to the feed bottle at filtration speed of $36 \mathrm{~mL} / \mathrm{min}$. As more filtrate was generated, the concentration of retentate increased. Once the retentate volume reached $1 \mathrm{~mL}$, purification was stopped. The purified sample was assessed for particle size distribution and zeta potential. Between purification of batches, the TFF system was cleaned by 1-h continuous circulation of $0.1 \mathrm{M} \mathrm{NaOH}$ followed by flushing with a large volume of water $(\geq 1 \mathrm{~L})$.

\subsection{Characterisation of solid lipid nanoparticles}

\subsubsection{Characterisation of particle size and zeta potential.}

The dynamic light scattering (DLS) technique was used to report the intensity mean diameter (z-average) and the polydispersity of all solid lipid nanoparticles formulations (Malvern Zetasizer Nano-ZS (Malvern Instruments, Worcs., UK)). The measurements of particles size and polydispersity were carried out at $25^{\circ} \mathrm{C}$ in $\operatorname{Tris}$ buffer (1:10 dilution, $10 \mathrm{mM}$, pH 7.4). Liposome zeta potential was measured in Tris buffer (1:10 dilution, $10 \mathrm{mM}, \mathrm{pH}$ 7.4) using the Malvern Zetasizer Nano-ZS (Malvern Instruments, Worcs., UK). All measurements were undertaken in triplicates. Furthermore, The Zetasizer AT (Malvern Instruments, Worcs., UK) was used as an on-line measurement of particle size. $2.5 \mathrm{~mL}$ of samples were diluted 1:10 in Tris buffer (1:10 dilution, $10 \mathrm{mM}, \mathrm{pH}$ 7.4) at $25{ }^{\circ} \mathrm{C}$ and the volume was let circulating between the mixing tank and the homogenizer, until the measurement was completed. Data obtained with the two instruments were compared.

\subsubsection{Lipid recovery}

Lipid recovery has been performed adding 1,1'-Dioctadecyl-3,3,3',3'-Tetramethylindocarbocyanine Perchlorate (DilC) $0.2 \% \mathrm{~mol}$ total lipid concentration, solved in the melt lipid before being loaded in the Microfluidizer. DilC sample fluorescence was measured before and after TFF (PolarStar, BMG LABTECH GmbH). Lipid quantification was achieved by referring to a calibration curve with a linearity of $R 2=0.995$. All measurements were within the level of detection and level of quantification. 


\subsubsection{Protein loading quantification}

The loading efficiency was measured using reverse phase HPLC (Agilent 1100 Series). The experiment was performed with a mobile phase of TFA $0.1 \%$ and Methanol with $0.08 \%$ TFA with a flow rate of $2.0 \mathrm{~mL} / \mathrm{min}, \lambda \max$ of $215 \mathrm{~nm}$. At these conditions the OVA retention time is $9.6 \mathrm{~min}$. The particles were destructed using a solution of IPA: TRIS 50:50 vol/vol. The solution was left at room temperature for 1 hour to achieve the complete particle dissolution. Then $1 \mathrm{~mL}$ of that solution was used for HPLC. The protein concentration was measured by reference to a calibration curve with a linearity of $\mathrm{R} 2=0.999$. All measurements were within the level of detection and level of quantification.

\subsection{In vitro release of protein from solid lipid nanoparticles}

For the release study of ovalbumin from solid lipid nanoparticles, nanoparticles were prepared using Microfluidizer (number of passes 5, pressure 25000 psi). All formulations were dialysed against $80 \mathrm{~mL}$ PBS pH 7.4 at $37^{\circ} \mathrm{C}$ (membrane cut off $300 \mathrm{KDa}$ ). The absorbance of aliquots from the outer buffer was analysed at different time points (up to 48 h) using NanoDrop 2000c UV-Vis spectrophotometer (Thermo Fisher Scientific Inc). The amount of released OVA was detected by measuring the protein absorbance at $230 \mathrm{~nm}$ (NanoDrop 2000c, UVVis Spectrophotometer) and related these values to the concentration using a calibration curve (linearity R2 = 0.998).

\subsection{Statistical analysis}

Unless stated otherwise, the results were calculated as mean \pm standard deviation (SD). ANOVA followed by Tukey post hoc analysis was performed for comparison and significance was acknowledged for $p$ values less than 0.05. All the calculations were made using Excel (Excel Software and Systems Pvt. Ltd.).

\section{Results}

\subsection{High-throughput manufacturing of solid lipid nanoparticles via high shear mixing}

Solid lipid nanoparticles consisting of Tristearin and mPEG-DSPE-2000 were formulated using High Shear Mixing method. The aim was to optimise parameters to control particle size by varying the operating pressure from 20,000 to 30,000 psi as well as the number of circulation cycles from 1 to 5 . Figure $1 \mathrm{~A}$ demonstrates that all particles produced by Microfluidizer processor had a diameter of $250 \mathrm{~nm}$ or below with a polydispersity index between 0.2 and 0.3. The results also show that changes in pressure values between 20,000 and 30,000 psi did not significantly influence particles size; however, at pressures of 20,000 psi the variability within the particle size was the lowest (Figure 1A) therefore demonstrating that this pressure can be adopted to produce solid lipid nanoparticles. Furthermore, increasing the number of cycles did not significantly reduce the particle size and at 20,000 psi particles of around $200 \mathrm{~nm}$ and polydispersity around 0.25 were formed irrespective of the number of passes demonstrating the particles are easily formed via this method. When considering the zeta potential of the formulations, all solid lipid nanoparticles were anionic in nature, as would be expected given their composition (approximately - 20 to $-30 \mathrm{mV}$; Figure $1 \mathrm{~B}$ ) and these values were not significantly affected by either number of cycles or applied pressure. 
Table 1. Examples of solid lipid nanoparticles formulations and their method of manufacture.

\begin{tabular}{|c|c|c|c|c|}
\hline $\begin{array}{l}\text { Manufacturing } \\
\text { method }\end{array}$ & Formulation & Drug & LE\% & Ref. \\
\hline \multirow{2}{*}{$\begin{array}{l}\text { double emulsion } \\
\text { method (w/o/w) } \\
\text { and solvent } \\
\text { evaporation }\end{array}$} & Lecithin and triglyceride & Catalase & 50 & 9 \\
\hline & Phosphatidylcholine and tripalmitin & Catalase & 78 & 10 \\
\hline $\begin{array}{l}\text { double emulsion } \\
\text { and melt } \\
\text { dispersion }\end{array}$ & $\begin{array}{l}\text { stearic acid or a mixture of stearic acid and } \\
\text { crodamol }\end{array}$ & $\begin{array}{l}\text { Sulforhodamine } \\
101\end{array}$ & 60 & 11 \\
\hline \multirow[t]{2}{*}{$\begin{array}{l}\text { high pressure } \\
\text { homogenisation } \\
\text { cold dispersion }\end{array}$} & $\begin{array}{l}\text { Witepsol E } 85, \text { Softisan } \\
\text { 142, propyleneglycol, Superpolystate, cetyl } \\
\text { alcohol }\end{array}$ & Lysozyme & 40 & 12 \\
\hline & stearic acid & Cyclosporine & $70-90$ & 13 \\
\hline $\begin{array}{l}\text { high pressure } \\
\text { homogenisation } \\
\text { hot dispersion }\end{array}$ & stearic acid & Cyclosporine & 80 & 14 \\
\hline \multirow[t]{3}{*}{$\begin{array}{l}\text { Warm } \\
\text { microemulsion }\end{array}$} & Egg lecithin, stearic acid & Thymopentin & $<5$ & 15 \\
\hline & mixture of stearic acid and Epikuron $200^{\circledR}$, & Cyclosporine & 13 & 16 \\
\hline & stearic acid and lecithin & Insulin & 38 & 17 \\
\hline \multirow[t]{2}{*}{ supercritical fluid } & Gelucire $^{\circledR} 50-02$ and Dynasan ${ }^{\circledR} 114$ & $\begin{array}{l}\text { bovine serum } \\
\text { albumin }\end{array}$ & 13 & 18 \\
\hline & Phosphatidylcholine and tristearin & $\begin{array}{l}\text { insulin and } \\
\text { recombinant }\end{array}$ & $<3$ & 19 \\
\hline
\end{tabular}




\begin{tabular}{|c|c|c|c|c|}
\hline & & $\begin{array}{l}\text { human growt } \\
\text { hormone }\end{array}$ & & \\
\hline & $\begin{array}{l}\text { tristearin/phosphatidylcholine/dioctyl } \\
\text { sulfosuccinate }\end{array}$ & Insulin & $<3$ & 20 \\
\hline $\begin{array}{l}\text { Solvent } \\
\text { displacement }\end{array}$ & Monostearin & Gonadorelin & 50 & 21 \\
\hline & Lecithin & Insulin & 27 & 22 \\
\hline $\begin{array}{l}\text { Solvent } \\
\text { evaporation }\end{array}$ & glyceryl tripalmitate & Thymocartin & $<50$ & 23 \\
\hline
\end{tabular}




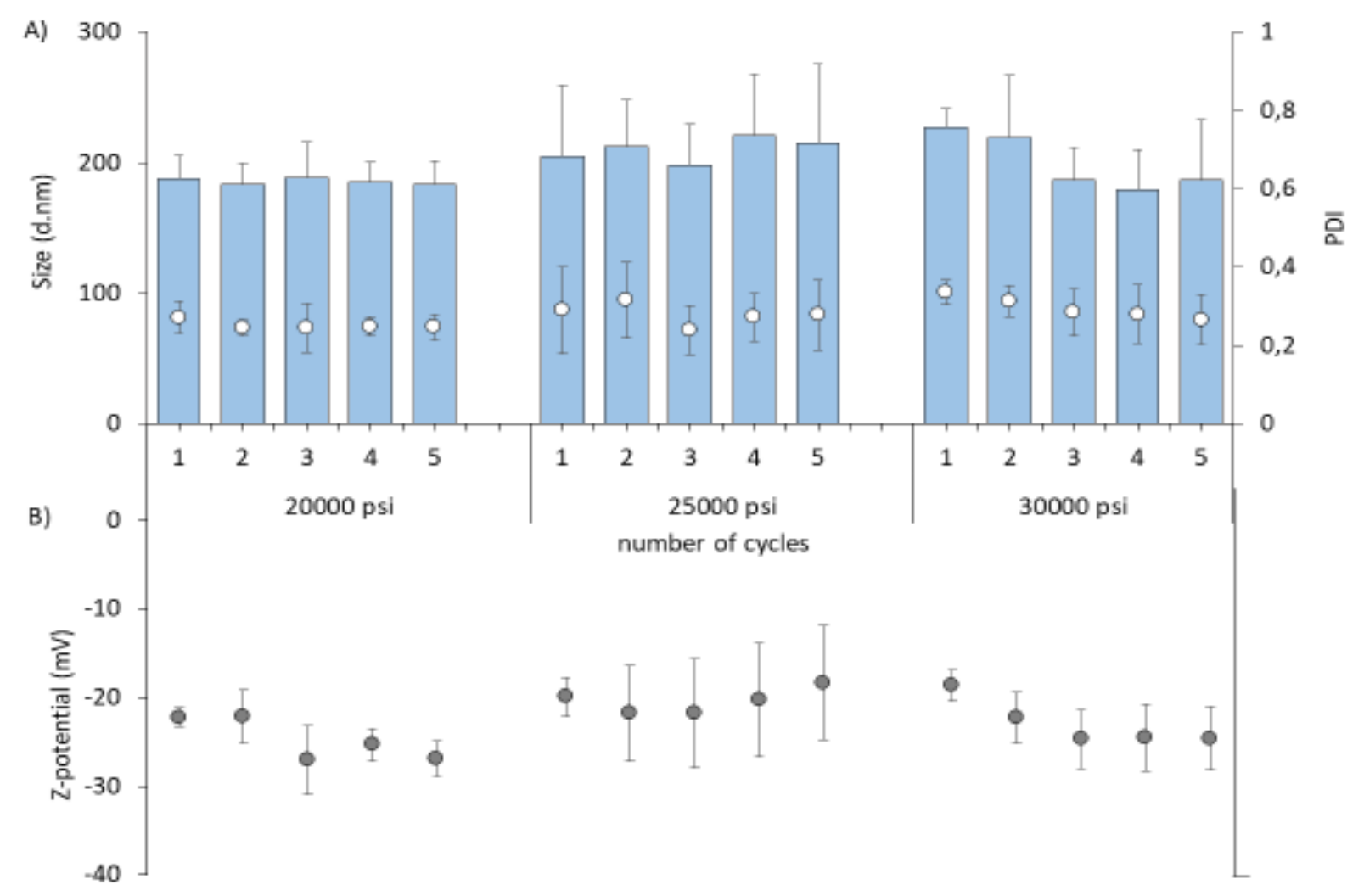

Figure 1. The effect of processing pressure and passes on SLN attributes. A) Size (columns), polydispersity (dots) and B) Z-potential of Tristearin: mPEG-DSPE SLNs obtained with Microfluidizer processor. Sample with pressure from 20000 to 30000 psi as well as cycles number from 1 to 5 had been tested. Results are expressed as the means of three experiments \pm S.D. 

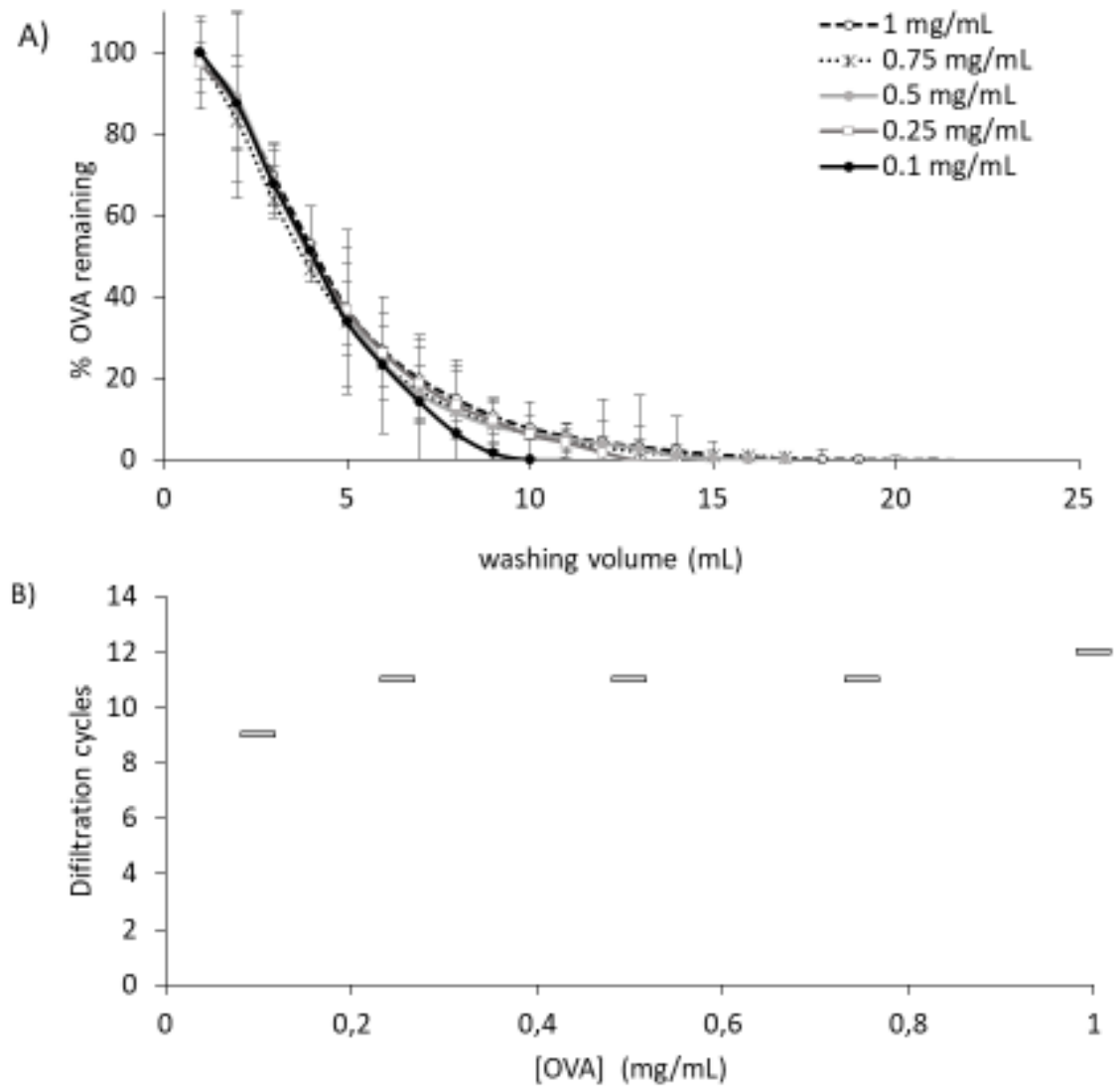

Figure 2. Purification and removal of non-incorporated protein via TFF. A) Percentage of remained OVA (mg/mL) after 20 washes at initial protein concentrations from 0.1 to $1 \mathrm{mg} / \mathrm{mL}$. B) Minimum number of difiltration cycles required to have a protein remained concentration below $5 \%$ (w/w). Results are expressed as the means of three experiments \pm S.D. 
A)

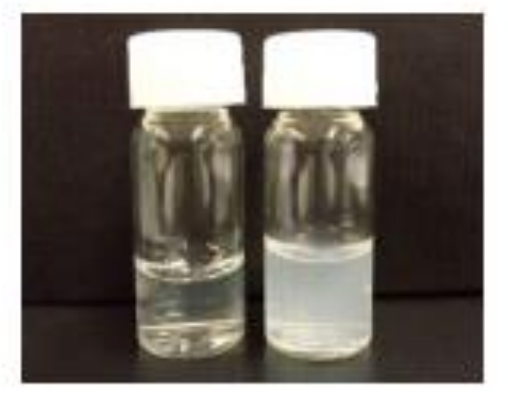

B)

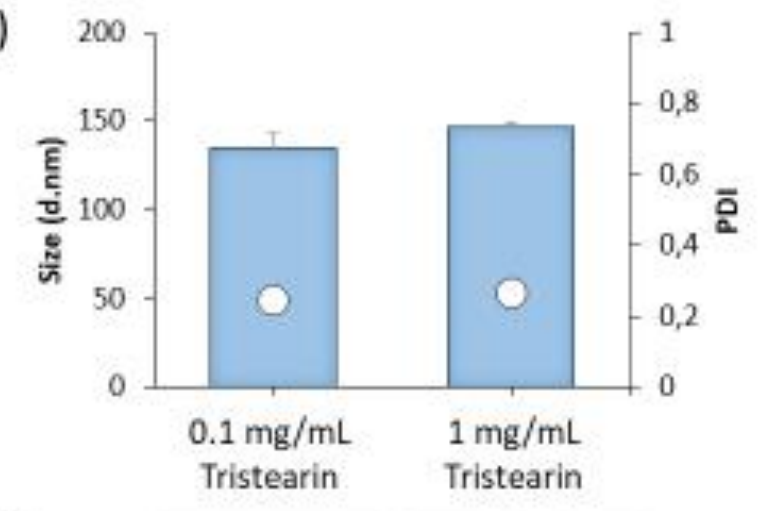

C)
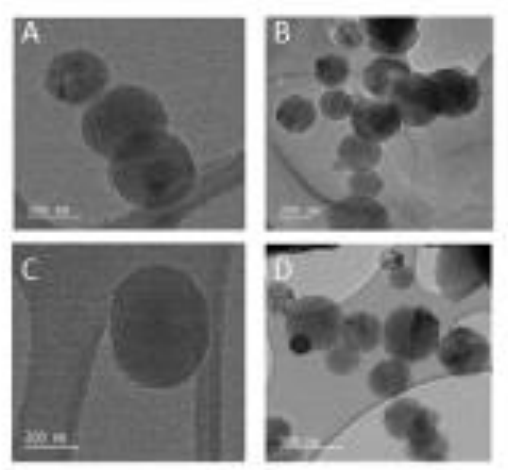

Figure 3. Production and at-line monitoring of SLNs after production via Microfluidizer processor after concentration via TFF in terms of A) visual appearance, B) Size (columns) and PDI (dots) of Tristearin: PEG SLNs before and after 10 times TFF concentration and C) cryoTEM images of Tristearin: PEG SLNs made by Microfluidizer processor before (on the left) and after (on the right) 10 times TFF concentration. Where appropriate, results are expressed as the means of three experiments \pm S.D. 


\subsection{Development of a high-throughput purification of solid lipid nanoparticles and in-line particle size monitoring}

To support the rapid purification and concentration of solid lipid nanoparticles, we applied tangential flow filtration (TFF). Initially, the TFF process was optimized to ensure effective removal of non-incorporated protein with protein concentrations of 0.1 to $1 \mathrm{mg} / \mathrm{mL}$ being mixed with pre-formed solid lipid nanoparticles and the removal of Ovalbumin measured. The results in Figure 2A demonstrate that across this range the purification process was similar with 12 difiltration cycles effectively removing non-loaded protein (Figure 2B). This process was then used to purify solid lipid nanoparticles prepared with OVA loaded. The lipid recovery and the SLN attributes (size, pdi, zp and protein loading) was measured for Tristearin: PEG SLNs (5:1 w/w) after purification via this TFF protocol (Table 2) with the SLNs being approximately $140 \mathrm{~nm}$ in size with a PDI of 0.2 with high protein loading $(100 \mu \mathrm{g} / \mathrm{mL})$ and high particle recovery was $96 \%$ (Table 2). The SLNs were also subjected to a 50 times concentration step via TFF, and there was no significant change in particle size and PDI (Figure 3B) or morphology (Figure 3C).

An important parameter in the development of effective manufacturing is the ability to rapidly monitor critical quality attributes of a product and in the case of nanoparticles, particle size is a key attribute. Therefore, we investigated the potential to monitor the particle size of our SLNs using the Zetasizer AT which offers on-line measurement of particle size using Dynamic Light Scattering to enable read time monitoring of the particle production. To achieve this, we set up the system at-line, such that samples could be tested during production as a process monitoring control or alternatively at the end of the production as a quality control. We compared this to the standard off-line particle sizing (Malvern Zetasizer). Figure 4 outlines the set-up and demonstrates that continuous monitoring of the particles size and polydispersity after TFF purification and concentration was achieved with no significant difference in particle size when measure off-line and at-line.

\subsection{Manufacture of protein-loaded solid lipid nanoparticles}

To assess the ability of the M110-P Microfluidizer processor as a potential high throughput manufacturing method for protein loaded lipid particles production, we formulated Tristearin:PEG SLNs in presence of different protein (Ovalbumin -OVA) concentrations. As it shown in figure 5A increasing the protein concentration had an impact on particles attributes with higher protein concentrations increasing the particle size with high variability $250 \pm 100 \mathrm{~nm}$ in size and a PDI of $0.4 \pm 0.05$. However initial OVA concentrations of up to $0.5 \mathrm{mg} / \mathrm{mL}$ has no significant impact on particle size (184 $\pm 31 \mathrm{~nm}$ and a PDI of $0.36 \pm 0.03)$ similar to particles formulated with initial OVA concentrations of $0.1 \mathrm{mg} / \mathrm{mL}$ OVA concentration (Figure $5 \mathrm{~A}$ ). The initial protein concentration did not impact on zeta potential with all particles being around - 30 to - $35 \mathrm{mV}$ (Figure 5B) and OVA loaded within the SLNs could be increased up to a maximum of $100 \mu \mathrm{g} / \mathrm{mL}$ for the given lipid concentration (Figure 5C).

Finally, we tested the impact of increasing the amount of MPEG within the SLNs given that low levels of PEG may be useful in the formulation of vaccine delivery systems whilst high levels of PEG can be useful for avoiding rapid clearance from the circulation. As shown in Figure 6, increasing the amount of PEG had no significant effect on particle size, $\mathrm{zp}$, protein loading and release profiles, suggesting that these systems can be prepared with low and high degrees of Pegylation without impacting on the particle size, PDI, loading and release properties. 

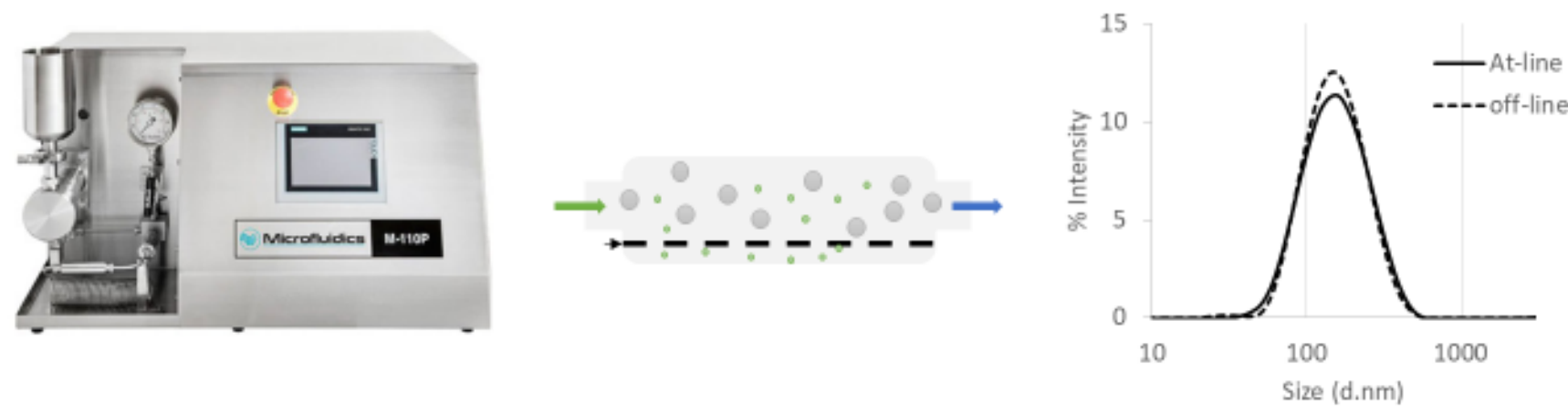

Manufacture

Purify

Monitor

Figure 4. Production and at-line monitoring of SLNs after production via Microfluidizer processor. SLNs were produced, purified via TFF and the particle size measured by circulation between the mixing tank and the homogenizer, until complete detection. Data obtained with al-line and off-line dynamic light scattering were compared. 
Table 2. solid lipid nanoparticles attributes after purification via TFF. Results represent mean $\pm S D, n=3$.

\begin{tabular}{cc}
\hline Solid lipid nanoparticles attributes \\
\hline Size & $142 \pm 3 \mathrm{~nm}$ \\
\hline PDI & $0.23 \pm 0.01$ \\
\hline Protein loading capacity & $100 \pm 24 \mu \mathrm{g} / \mathrm{mL}$ \\
\hline Particle recovery & $96 \%$ \\
\hline
\end{tabular}



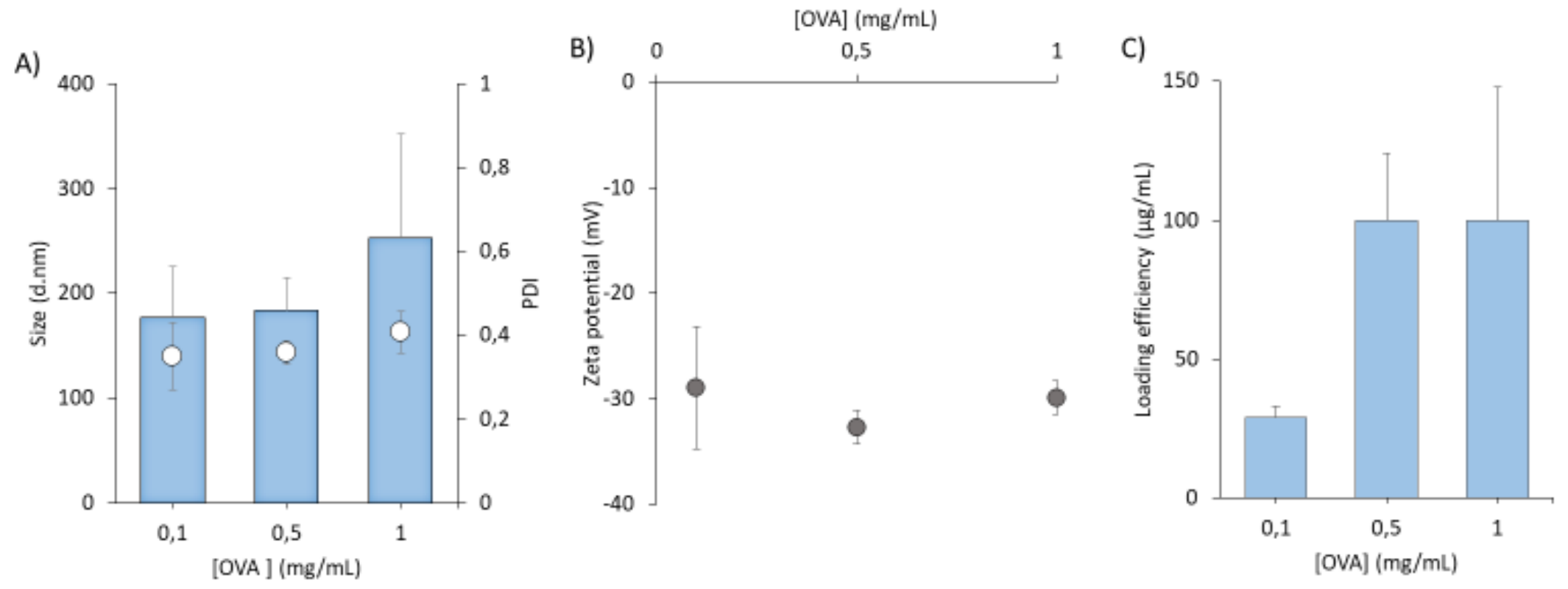

Figure 5. OVA-loaded solid lipid nanoparticles made by Microfluidizer processor a) Size (columns), PDI (dots) and b) Zeta potential and c) Loading efficiency of Tristearin: mPEG-DSPE SLNs expressed as percentage of the initial protein amount $(\mu \mathrm{g} / \mathrm{mL})$. Results are expressed as the means of three experiments \pm S.D. 

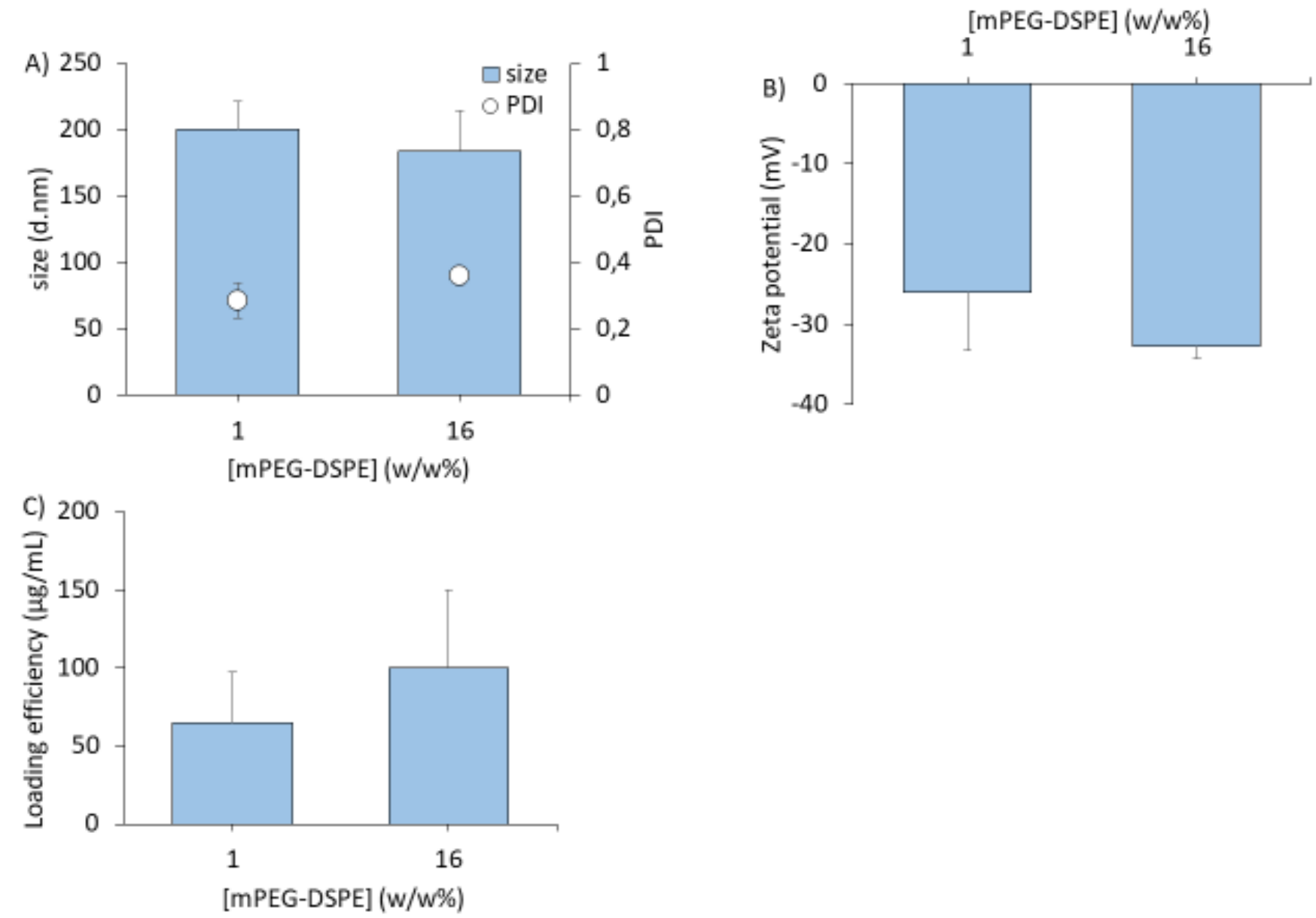

Figure 6. The effect of PEG on SLN attributes A) size and PDI, B) Zeta Potential and C) protein loading. The initial loading protein concentration used to produce the formulation was $0.5 \mathrm{mg} / \mathrm{mL}$. Results are expressed as the means of three independent experiments \pm S.D. 


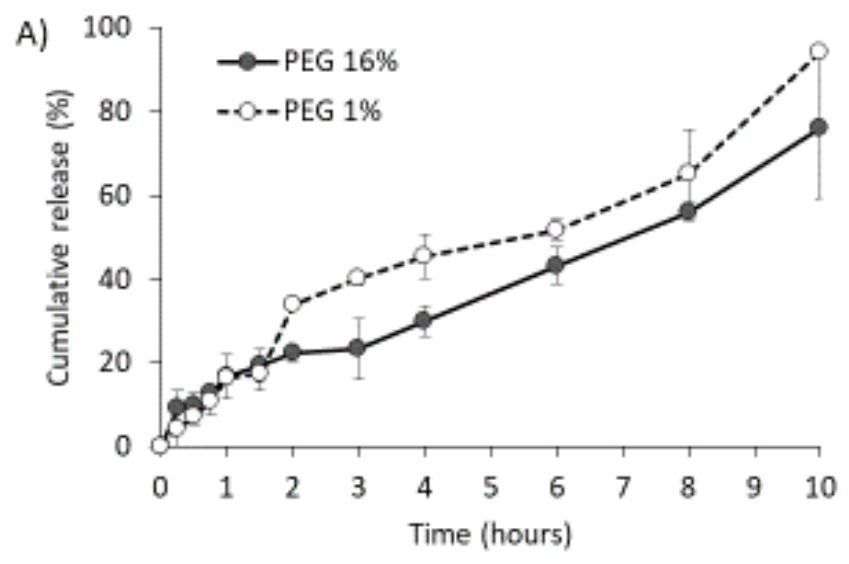

B)

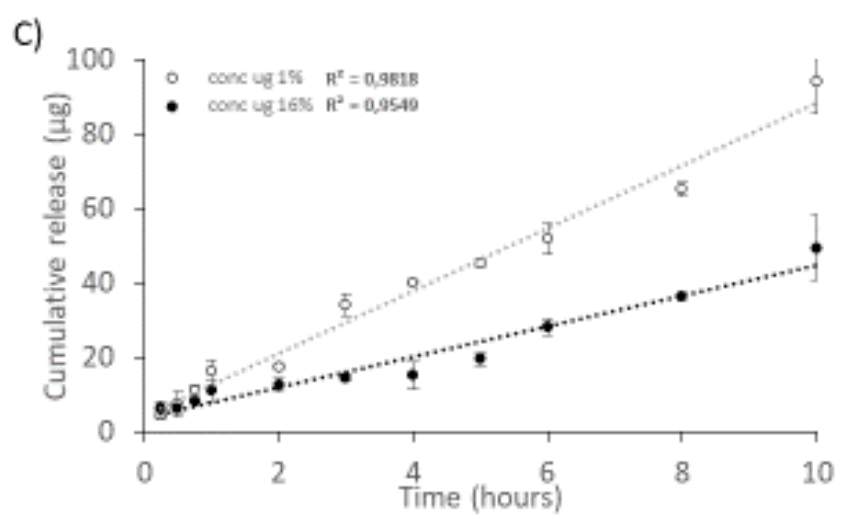

Figure $7 \mathrm{~A}$ ) The cumulative release profile of OVA under physiological conditions from SLNs (PBS buffer, $\mathrm{pH}=7.4$, at $37^{\circ} \mathrm{C}$ ) from formulations containing either $1 \%$ (open circle) or $16 \%$ (black circle) w/w PEG. The initial loading protein concentration used to produce the formulation was $0.5 \mathrm{mg} / \mathrm{mL}$. Results represent percentage cumulative release of initially incorporated OVA. Data was also replotted according to B) zero-order or C) first-order. Results are expressed as the means of three independent experiments \pm SD. 


\section{Discussion}

Solid lipid nanoparticles offer a range of advantages for drug delivery due to their biocompatibility, biodegradability and physical stability. Despite these advantages, their application has been limited by the lack of cost-effective and scalable methods for their preparation (Table 1). Furthermore, the loading of hydrophilic, biologically active compounds is challenging, due to the intrinsic lipophilic nature of solid lipid nanoparticles. High shear mixing is commonly applied this method for particles size reduction with decreasing particles size occurring after a few recirculation cycles ${ }^{(38-39)}$. For example, liposomes made by 1,2-dipalmitoyl-sn-glycero-3phosphocholine, 1,2-dipalmitoyl-sn-glycero-3-phosphoglycerol and cholesterol reached size values of around 80 $\mathrm{nm}$ and PDI 0.11 after 12 cycles at 10,000 psi (40). Similarly, liposomes prepared by this method and formulated from hydrogenated soybean phosphatidylcholine and N-(Carbonyl-methoxypolyethyleneglycol2000)-1,2distearoyl-sn-glycero-3-phosphoethanolamine (MPEG2000-DSPE) were highly homogeneous with average diameter of 90-110 $\mathrm{nm}^{(41)}$. Generally, solid lipid nanoparticles tend to be larger in size and previous studies using three recirculating cycles in microfluidizer platform at 10,000 psi produced Tristearin based SLNs at around 200 $\mathrm{nm}$ with low polydispersity ${ }^{(42)}$ and within our studies (Figure 1) we demonstrate this method can be employed to produce SLNs in a high through-put and efficient production of SLNs at flow rates of up to $155 \mathrm{~mL} / \mathrm{min}$ depending on the process pressure.

In addition to their productions, solid lipid nanoparticles (and other nanoparticles) generally require purification to remove non-entrapped drug and tangential flow filtration offers a scalable process. Therefore, with has been exploited in our manufacturing process to effectively remove un-entrapped protein with our SLNs being purified and retaining their physico-chemical attributes (Figure 2, 3 and 4) with good particle recovery (Table 2). TFF has recently emerged as an innovative purification method, and several studies describe the effective purification and concentration of nanoparticles using tangential flow filtration ${ }^{(43-44)}$. For instance, nanoparticles composed of poly (D, L-lactide-co-glycolide) and polyvinyl alcohol (PVA) were purified by tangential flow filtration with a 300K MWCO membrane and the purified particle dispersions were stable and free of aggregation ${ }^{(45)}$. Moreover, it was demonstrated that phosphatidylcholine and cholesterol based liposomes were successfully purified by TFF application, with no change in particles size (approximately $115 \mathrm{~nm}$ ) and PDI (0.15) and a total lipid recovery after diafiltration ${ }^{(46)}$. We then took advantage of TFF to remove unbounded protein; Ovalbumin was used as model biomolecule which is proven to be biologically active as immunostimunant ${ }^{(47-48)}$, thus it can be applicable in the development of both drug and vaccine delivery formulation assessment. As a water soluble compound, its encapsulation in lipid based systems is challenging. Therefore, the choice of OVA is a good rational to challenge our production method. Herein, we proved that protein loading solid lipid nanoparticles could be manufactured, purified and concentrated using scalable and cost-effective methods, without any alterations in particles physicochemical properties. Within these studies, we also demonstrate that high protein concentrations destabilize the inner colloidal structure of particles, increasing sizes and inducing aggregation. ${ }^{(51-53)}$ Many factors can physically destabilize solid lipid nanoparticles leading to significant increase in particles size and consequent aggregation. The use of PEG in particles formulation is a well-known technique to improve physical stability of

particles. PEG generates hydrophilic polymeric coating and PEG chains help to keep particles separated. ${ }^{(54-56)}$ The presence of PEG shield favours particles repulsion thus reducing particle growth and collapse.

In vitro release study from our SLNs revealed that protein release increased over time with no burst effect (Figure 6 ); after 10 hours all protein content ( $>80 \%$ of the initial concentration) was released irrespective of the PEG 
content. Drug release from almost all the SLNs follows Weibul and Higuchi equations better than first-order equation ${ }^{(57-58)}$. The pseudo-first order release kinetics maintains the drug concentration in the blood or target tissue at a desired value longer ${ }^{(59)}$. Furthermore, the presence of high amount of PEG reduced kinetics of the process: several coherent explanations could be given to this phenomenon. According to Stocks-Einstein equation ${ }^{(60)}$, diffusion coefficient is inversely proportional to solution viscosity: diffusion could be slowed down by increasing solution viscosity. The presence of polyethylene glycol molecules on particles surface enhanced the bulk viscosity of water reducing the speed at which OVA could cross the lipid barrier. Secondly, PEG chains are very flexible and they give larger hydrodynamic radius in aqueous media. According to Fick's first law of diffusion ${ }^{(61)}$, the rate of diffusion is related to membrane thickness, in a reverse proportional manner. The presence of polymer increased the thickness of particles surface and reduced OVA diffusion speed. All these findings emphasise the applicability of lipid particles and microfluidizer as a valid alternative for proteins production.

\section{Conclusions}

The work reported here demonstrates that we can effectively formulate, manufacture, purify and monitor the particle size of SLNs produced in process that scales from bench to clinic. Within this study we have formulated SLNs at approx. $200 \mathrm{~nm}$ or below containing low and high PEGylation (1 and 16 mol\%) and incorporating OVA. The modification of the PEGylation will allow us to explore these delivery systems as potential adjuvants (low PEGylation) and for therapeutic drug delivery (high PEGylation). We are able to manufacture the SLNs rapidly (2 cycles) and at a low pressure (20,000 psi) and removal of non-entrapped protein achieved after 12 diafiltration cycles. This work outlines a simple and scalable manufacturing process that can enhance the translation of SLNs from laboratory tools to clinical products.

\section{Acknowledgements.}

This work was funded by the European Commission Project Leveraging Pharmaceutical Sciences and Structural Biology Training to Develop 21 ${ }^{\text {st }}$ Century Vaccines (H2020-MSCA-ITN-2015 grant agreement 675370). We would like to thank Mircofluidics Inc, Westwood, Massachusetts, US for providing access to the M-110P Microfluidizer ${ }^{\circledR}$ and Malvern Panalytical for the use of the Zetasizer AT.

\section{Supporting information Available}

Data presented in this publication can be found at DOI 10.2174/2211738507666190925112942 


\section{References}

[1] A zur Mühlen, C Schwarz, W Mehnert; Solid lipid nanoparticles (SLN) for controlled drug delivery - Drug release and release mechanism; European Journal of Pharmaceutics and Biopharmaceutics - Volume 45, Issue 2, March 1998, Pages 149-155

[2] Muller RH, Runge SA. Solid lipid nanoparticles (SLN) for controlled drug delivery. In: Benita S, editor. Submicron emulsions in drug targeting and delivery. Amsterdam: Harwood Academic Publishers; 1998. pp. 21934.

[3] Müller RH, Radtke M, Wissing SA. Nanostructured lipid matrices for improved microencapsulation of drugs. Int. J. Pharm. 2002;242(1-2):121-8

[4] Solid lipid nanoparticles (SLN) for controlled drug delivery-a review of the state of the art RH MuÈller, K MaÈder, S Gohla - European Journal of Pharmaceutics and Biopharmaceutics, 3 July 2000

[5] Müller R.H., Mäder K, Gohla S. Solid lipid nanoparticles (SLN) for controlled drug delivery - a review of the state of the art; European Journal of Pharmaceutics and Biopharmaceutics-Volume 50, Issue 1, 3 July 2000, Pages 161-177

[6] Tristearin in Linstrom, P.J.; Mallard, W.G. (eds.) NIST Chemistry WebBook, NIST Standard Reference Database Number 69. National Institute of Standards and Technology, Gaithersburg MD. http://webbook.nist.gov (retrieved 2014-06-19)

[7] Abou-Saleh R.H. Swain M. Evans S.D., Thomson N.H. Poly(ethylene glycol) Lipid-Shelled Microbubbles: Abundance, Stability, and Mechanical Properties Langmuir 30(19) · April 2014

[8] Battaglia L., Gallarate M.,Panciani P.P., Ugazio E., Sapino S.,Peira E. Chirio D. ; Techniques for the Preparation of Solid Lipid Nano and Microparticles; Nanotechnology and Nanomaterials " "Application of Nanotechnology in Drug Delivery".

[9] Qi C., Chen Y., Jing Q.,Wang X. Preparation and Characterization of Catalase-Loaded Solid Lipid Nanoparticles Protecting Enzyme against Proteolysis. Int J Mol Sci. 2011; 12(7): 4282-4293

[10] Qi C, Chen Y, Huang JH, Jin QZ, Wang XG. Preparation and characterization of catalase-loaded solid lipid nanoparticles based on soybean phosphatidylcholine. J Sci Food Agric. 2012;92(4):787-793.

[11] L B Peres, L.B Peres, de Araújo PHH, Sayer C. Solid lipid nanoparticles for encapsulation of hydrophilic drugs by an organic solvent free double emulsion technique. Colloids Surf B Biointerfaces. 2016 Apr 1;140:317-323. doi: 10.1016/j.colsurfb.2015.12.033. Epub 2015 Dec 29.

[12] A.J. Almeida, S. Runge, R.H. Müller, Peptide-loaded solid lipid nanoparticles (SLN): influence of production parameters, Int. J. Pharm. 149 (1997) 255-265

[13] R.H. Müller, V. Ravelli, S. Runge, Pharmaceutical cyclosporin formulation with improved biopharmaceutical properties, improved physical quality and greater stability, and method for producing said formulation, Deutsche Patentanmeldung 198, 19, 273 (1998). 
[14] Q. Zhang, G. Yie, Y. Li, Q. Yang, T. Nagai, Studies on the cyclosporine A loaded stearic acid nanoparticles, Int. J. Pharm. 200 (2000) 153-159.

[15] S. Morel, E. Ugazio, R. Cavalli, M.R. Gasco, Thymopentin in solid lipid nanoparticles, Int. J. Pharm. 132 (1996) 259-261

[16] E. Ugazio, R. Cavalli,M.R. Gasco, Incorporation of cyclosporine A in solid lipid nanoparticles (SLN), Int. J. Pharm. 241 (2002) 341-344

[17] N. Zhang, Qi. Ping, G. Huang, W. Xu, Y. Cheng, X. Han, Lectin-modified solid lipid nanoparticles as carriers for oral administration of insulin, Int. J. Pharm. 327 (2006) 153-159.

[18] I. Ribeiro dos Santos, J. Richard, B. Pech, C. Thies, J.P. Benoit, Microencapsulation of protein particles within lipids using a novel supercritical fluid process, Int. J. Pharm. 242 (2002) 69-78.

[19] SR. Mao, YZ. Wang, HY Ji, DZ Bi. Preparation of solid lipid nanoparticles by microemulsion technique. Yao Xue Xue Bao. 38(2003) 624-636.

[20] Salmaso, Elvassore N., Bertucco A., Caliceti P Production of solid lipid submicron particles for protein delivery using a novel supercritical gas-assisted melting atomization process. https://doi.org/10.1002/jps.21434|

[21] F.Q. Hu, Y. Hong, H. Yuan, Preparation and characterization of solid lipid nanoparticles containing peptide, Int. J. Pharm. 273 (2004) 29-35.

[22] N. Zhang, Qi. Ping, G. Huang, W. Xu, Y. Cheng, X. Han, Lectin-modified solid lipid nanoparticles as carriers for oral administration of insulin, Int. J. Pharm. 327 (2006) 153-159.

[23] H. Reithmeier, J. Herrmann, A. Gopferich, Lipid microparticles as a parenteral controlled release device for peptides, J. Control. Release 73 (2001) 339-350.

[24] Mayhew, E., Lazo, R., Vail, W., King, J., Green, A., 1984. Characterization of liposomes prepared using a microemulsifier. Biochim. Biophys. Acta (BBA)-Biomembr. 775, 169-174.

[25] Washington, C., Davis, S., 1988. The production of parenteral feeding emulsions by microfluidizer. Int. J. Pharm. 44, 169-176.

[26] Saheki, A., Seki, J., Nakanishi, T., Tamai, I., 2012. Effect of back pressure on emulsification of lipid nanodispersions in a high-pressure homogenizer. Int. J. Pharm. 422, 489-494.

[27] Mahdi Jafari, S., He, Y., Bhandari, B., 2006. Nano-emulsion production by sonication and microfluidizationa comparison. Int. J. Food Prop. 9, 475-485

[28] Sorgi, F.L., Huang, L., 1996. Large scale production of DC-Chol cationic liposomes by microfluidization. Int. J. Pharm. 144, 131-139.

[29] Bodmeier, R., Huagang, C., 1990. Indomethacin polymeric nanosuspensions prepared by microfujidization. J. Controlled Release 12, 223-233.

[30] Sani, S.N., Das, N.G., Das, S.K., 2009. Effect of microfluidization parameters on the physical properties of PEG-PLGA nanoparticles prepared using high pressure microfluidization. J. Microencapsul. 26, 556-561. 
[31] Siqueira, G., Bras, J., Dufresne, A., 2009. New process of chemical grafting of cellulose nanoparticles with a long chain isocyanate. Langmuir 26, 402-411.

[32] Takahashi, M., Kitamoto, D., Asikin, Y., Takara, K., Wada, K., 2009. Liposomes encapsulating Aloe vera leaf gel extract significantly enhance proliferation and collagen synthesis in human skin cell lines. J. Oleo Sci. 58, 643650 .

[33] Thompson, A., Singh, H., 2006. Preparation of liposomes from milk fat globule membrane phospholipids using a microfluidizer. J. Dairy Sci. 89, 410-419

[34] Laye, C., McClements, D. J., \& Weiss, J. (2008). Formation of biopolymer-coated liposomes by electrostatic deposition of chitosan. Journal of Food Science, 73, N7e15.

[35] Gibis M, Zeeb B, Weiss J. Formation, characterization, and stability of encapsulated hibiscus extract in multilayered liposomes. Food Hydrocolloids 38 (2014) $28 \mathrm{e} 39$

[36] T. Lajunen , K. Hisazumi , T. Kanazawa , H. Okada , Y. Seta , M. Yliperttula , A. Urtti ,Y. Takashima. Topical drug delivery to retinal pigment epithelium with microfluidizer produced small liposomes. European Journal of Pharmaceutical Sciences 62 (2014) 23-32

[37] Gavi E. Kubicki D. Padron G.A. Özcan-Taskın N.G. Breakup of nanoparticle clusters using Microfluidizer M110P. Chemical Engineering Research and Design 132(2018)902-912

[38] Salminen H., Helgason T., Kristinsson B. Kristbergsson K., Weiss J., Tuning of shell thickness of solid lipid particles impacts the chemical stability of encapsulated $x-3$ fish oil; Journal of Colloid and Interface Science 490 (2017) 207-216.

[39] Asumadu-Mensah A., Smith K.W., Ribeiro H. S., Solid Lipid Dispersions: Potential Delivery System for Functional Ingredients in Foods. Journal of Food Science 10.1111/1750-3841.12162

[40] Dalwadi G, Sunderland VB. Purification of PEGylated nanoparticles using tangential flow filtration (TFF). Drug Dev Ind Pharm 2007; 33: 1030-9.

[41] Cui J.X., Li C., Guo W., Li Y. Wang C., Zhang L., Zhang L., Hao Y , Wang Y. Direct comparison of two pegylated liposomal doxorubicin formulations: Is AUC predictive for toxicity and efficacy? Journal of Controlled Release 118 (2007) 204-215

[42] Salminen H., Helgason T., Kristinsson B., Kristbergsson K., Weiss J. Tuning of shell thickness of solid lipid particles impacts the chemical stability of encapsulated x-3 fish oil. Journal of Colloid and Interface Science 490 (2017) 207-216

[43] 12) He Z., Hu Y., Nie T., Tang H., Zhy J., Chen K., Liu L., Leong W.K., Chen Y., Hai-Quan M. Size-controlled lipid nanoparticle production using turbulent mixing to enhance oral DNA delivery. Acta Biomaterialia /10.1016/j.actbio.2018.09.047

[44] Dalwadi G. Sunderland V.B.Purification of PEGylated Nanoparticles Using Tangential Flow Filtration (TFF). Drug Development and Industrial Pharmacy 33(9):1030-9 · October 200 
[45] Dalwadi G1, Benson HA, Chen Y. Comparison of diafiltration and tangential flow filtration for purification of nanoparticle suspensions. Pharm Res. 2005 Dec;22(12):2152-62

[46] Dimov N., Kastner E.,Hussain M., Perrie Y. Szita N. Formation and purification of tailored liposomes for drug delivery using a module-based micro continuous-flow system. Scientific Reportsvolume 7, Article number: 12045 (2017)

[47] M L Conrad, A Ö Yildirim, S S Sonar, A Kılıç, S Sudowe, M Lunow, R Teich, H Renz, H Garn Comparison of adjuvant and adjuvant-free murine experimental asthma models. Clin Exp Allergy. 2009 Aug; 39(8): 1246-1254.

[48] Gupta A., A. Khajuria, J. Singh, S. Singh, K.A. Suri, G.N. Qazi. Immunological adjuvant effect of Boswellia serrata (BOS 2000) on specific antibody and cellular response to ovalbumin in mice. International Immunopharmacology 11 (2011) 968-975

[49] Kastner E., Kaur R., Lowry D., Moghaddam B., Wilkinson A., Perrie Y.High-throughput manufacturing of sizetuned liposomes by a new microfluidics method using enhanced statistical tools for characterization. International Journal of Pharmaceutics 477 (2015) 361-368

[50] McLaren D.G., Miller P.L., Lassman M.E.,Castro-Perez J.M., Hubbard B.K., Roddy T.P. An ultraperformance liquid chromatography method for the normal-phase separation of lipids. Analytical Biochemistry 414 (2011) 266-272

[51] van de Weert M.Hennink W.E., Jiskoot W., Protein Instability in Poly(Lactic-co-Glycolic Acid) icroparticles. Pharmaceutical Research 17(10):1159-1167.

[52] Hong S.S. Kim S.H., Lim S.J. Effects of triglycerides on the hydrophobic drug loading capacity of saturated phosphatidylcholine-based liposomes. International Journal of Pharmaceutics 483 (2015) 142-150.

[53] Colletier J.P., Chaize B. Winterhalter M.Fournier D.Protein encapsulation in liposomes: efficiency depends on interactions between protein and phospholipid bilayer. BMC Biotechnology 2002, 2:9

[54] Kenny, G.D., Kamaly, N., Kalber, T.L., Brody, L.P., Sahuri, M., Shamsaei, E., Miller, A.D. \& Bell, J.D., 2011. Novel multifunctional nanoparticle mediates siRNA tumour delivery, visualisation and therapeutic tumour reduction in vivo. J Control Release, 149, 111-6

[55] de Lima G.F., de Souza A.G., Rosa D.S.Effect of adsorption of polyethylene glycol (PEG), in aqueous media, to improve cellulose nanostructures stability. Journal of Molecular Liquids 268 (2018) 415-424

[56] Luangtana-anan M., Limmatvapirat S., Nunthanid J., Chalongsuk R., Yamamoto K. Polyethylene Glycol on Stability of Chitosan Microparticulate Carrier for Protein

[57] D.-B. Chen, T.-Z. Yang, W.-L. Lu, Q. Zhang. In vitro and in vivo study of two types of long-circulating solid lipid nanoparticles containing paclitaxel, Chem. Pharm. Bull. 49 (11) (2001) 1444- 1447.

[58] Venkateswarlu V., Manjunath K., Preparation, characterization and in vitro release kinetics of clozapine solid lipid nanoparticles. Journal of Controlled Release 95 (2004) 627-638

[59] Langer RS, Wise DL. Medical applications of controlled release, applications and evaluation. Eds. Vol. I and II. CRC Press: Boca Raton; 1984. 
[69] J. Brillo, A. I. Pommrich, A. Meyer. Relation between Self-Diffusion and Viscosity in Dense Liquids: New Experimental Results from Electrostatic Levitation.

[61] Fick, A. (1855). "On liquid diffusion". Poggendorffs Annalen. 94: 59. - reprinted in "On liquid diffusion". Journal of Membrane Science. 100: 33-38. 1995. doi:10.1016/0376-7388(94)00230- 